\title{
Projeto e planejamento de canteiro de obras no Brasil: Uma revisão sobre as boas práticas e ferramentas utilizadas
}

\author{
Project and planning of construction site in Brazil: A review on good practices and tools used \\ Proyecto y planificación de un sitio de construcción en Brasil: Una revisión de las mejores prácticas \\ y herramientas utilizadas
}

Recebido: 19/07/2021 | Revisado: 27/07/2021 | Aceito: 26/07/2021 | Publicado: 02/08/2021

Glêdson Pereira Lima

ORCID: https://orcid.org/0000-0003-1019-0963 Universidade Federal Fluminense, Brasil E-mail: limaarquitetura@gmail.com

Luiz Carlos Brasil de Brito Mello

ORCID: https://orcid.org/0000-0002-0367-4057 Universidade Federal Fluminense, Brasil E-mail: luiz.brasil@gmail.com

Goodry Saint Jean

ORCID: https://orcid.org/0000-0002-1808-6557 Universidade Federal Fluminense, Brasil E-mail: goodrysj@id.uff.br

Gustavo Oliveira Pinto

ORCID: https://orcid.org/0000-0002-1264-3228 Universidade Federal Fluminense, Brasil E-mail: gustavop@id.uff.br

\begin{abstract}
Resumo
O processo de gestão está presente em diferentes setores econômicos e permite uma tomada de decisão mais assertiva com alcance de melhores resultados. Este processo é dotado de melhores práticas e métodos que facilitam o desencadeamento de toda estrutura organizacional no que tange as atividades e entregas. Na construção civil o desenvolvimento de novas tecnologias, exigências de mercado e os desafios organizacionais na busca pela excelência têm levado empresas a repensarem seus sistemas de gestão. O objetivo deste trabalho é identificar as boas práticas e ferramentas utilizadas nos canteiros de obras no Brasil, conforme a percepção dos profissionais da construção civil, empreiteiros e demais empresas ligadas ao setor. A metodologia utilizada está baseada em um estudo bibliográfico por meio de trabalhos acadêmicos afim de fundamentar o estudo, bem como uma pesquisa de campo com profissionais de mercado nos mais diferentes níveis e cargos. Os resultados apontaram negligência em diversos aspectos, inclusive legais, para o desenvolvimento do projeto e planejamento de canteiro. Mostrou ainda, a baixa importância dada, a fase de planejamento, e a cultura do imediatismo e improviso, além da pressão pela etapa de produção e pela redução de custos. Foi possível verificar a falta de adoção de diretrizes e metodologia própria e eficaz. Por fim, contatou-se, mesmo assim, que boas práticas nos canteiros vêm sendo utilizadas, desde ferramentas simples até a aplicação de sistemas mais modernos, além do uso de tecnologias inovadoras. Constatou-se também, que o processo de planejamento e projeto do canteiro pode trazer maior produtividade, redução de desperdício e melhoria da qualidade na construção civil.
\end{abstract}

Palavras-chave: Gestão; Boas práticas; Canteiro de obras; Projeto; Planejamento.

\begin{abstract}
The management process is present in different economic sectors and allows for more assertive decision-making with better results. This process is endowed with best practices and methods that facilitate the triggering of the entire organizational structure regarding activities and deliverables. In civil construction, the development of new technologies, market demands, and organizational challenges in the pursuit of excellence has led companies to rethink their management systems. The objective of this work is to identify the best practices and tools used in construction sites in Brazil, based on the perception of civil construction professionals, contractors, and other companies related to the sector. The methodology used is based on a bibliographic study through academic works in order to support the study, as well as field research with market professionals at different levels and positions. The results showed negligence in several aspects, including legal, for the project development and construction site planning. It also showed negligence in the planning phase, and the culture of immediacy and improvisation, in addition to pressure for the production stage and cost reduction. It was possible to verify the lack of adoption of proper and effective guidelines and methodology. Finally, it was contacted, even so, that good practices have been used in the construction
\end{abstract}


sites, from simple tools to the application of more modern systems and the use of innovative technologies, and that the planning and design process of the construction site can bring greater productivity, reduction of waste and quality improvement in Civil Construction.

Keywords: Management; Good habits; Construction site, Project; Planning.

\section{Resumen}

El proceso de gestión está presente en diferentes sectores económicos y permite una toma de decisiones más asertiva con mejores resultados. Este proceso está dotado de mejores prácticas y métodos que facilitan el desencadenamiento de toda la estructura organizacional en cuanto a actividades y entregables. En la construcción civil, el desarrollo de nuevas tecnologías, las demandas del mercado y los desafíos organizacionales en la búsqueda de la excelencia han llevado a las empresas a repensar sus sistemas de gestión. El objetivo de este trabajo es identificar qué buenas prácticas y herramientas se utilizan en las obras de construcción en Brasil, de acuerdo con la percepción de los profesionales de la construcción civil, contratistas y otras empresas relacionadas con el sector. La metodología utilizada se basa en un estudio bibliográfico a través de trabajos académicos con el fin de apoyar el estudio, así como una investigación de campo con profesionales del mercado en diferentes niveles y puestos. Los resultados mostraron negligencia en varios aspectos, incluido el legal, para el desarrollo del proyecto y la planificación del sitio de construcción. También mostró negligencia en la fase de planificación, y la cultura de la inmediatez y la improvisación, además de la presión por la fase de producción y la reducción de costes. Se pudo comprobar la falta de adopción de directrices y metodología adecuadas y efectivas. Finalmente, se contactó, aun así, que se han utilizado buenas prácticas en los sitios de construcción, desde herramientas simples hasta la aplicación de sistemas más modernos y el uso de tecnologías innovadoras, y que el proceso de planificación y diseño de la obra puede traer mayor productividad, reducción de residuos y mejora de la calidad en la Construcción Civil.

Palabras clave: Gestión; Buenas practicas; Zona de obras; Proyecto; Planificación.

\section{Introdução}

A construção civil no Brasil é um dos setores que mais consome recursos, emprega maior força de trabalho e se utiliza de mais energia em seus processos. Beltrame (2013) destaca que o volume de recursos utilizados nas edificações consome $34 \%$ do fornecimento mundial de água, $66 \%$ de toda a madeira extraída, e sua operação consome mais de $40 \%$ de toda a energia produzida no mundo.

A Indústria da Construção Civil se destaca pela participação significativa na economia brasileira e com forte correlação do Produto Interno Bruto (PIB) do setor com o PIB nacional (Nunes et al., 2020). Nos últimos anos, os números denotam a pujança do setor, onde entre 2010 e 2013, o PIB da construção civil superou o PIB Brasil, porém, com forte queda nos anos posteriores e com uma leve recuperação de 2018 e 2019 (Bezerra, 2020). Já no ano de 2020 a queda do PIB do setor marcou 2,8\%, em função da pandemia, todavia, com expectativa de crescimento de 4,0\% para o ano seguinte (Empresa Brasil de Comunicação, 2021).

Segundo (Arantes, 2008), as exigências do mercado por sua vez têm levado muitas construtoras a remodelarem sua forma de gerir novos empreendimentos, enquanto vivemos a escassez de recursos, a alta no preço dos materiais, além das incertezas de mercado. Assim temos uma difusão dos conceitos de gestão nos canteiros, seja de qualquer tipo de construção, ou seja, o planejamento e o projeto se tornaram necessários para quantificar e qualificar os resultados da construção.

Os canteiros de obras podem ser subdivididos em três tipos de acordo com sua aplicabilidade. Os canteiros restritos são aplicados sobretudo em áreas urbanas em decorrência do espaço limitado estando estes alocados em determinado espaço. Os canteiros amplos estão presentes em grandes obras e ocupam espaços restritos no empreendimento. No entanto, apresentam maior flexibilidade no desenvolvimento das atividades. Por fim, os canteiros lineares são comuns em obras com limitação de acesso com longos cursos lineares, ou seja, o espaço reservado está limitado a esta dimensão (Souza, 2000).

Assim, os canteiros ganham importância, pois são responsáveis pela alocação e distribuição de materiais, mão-de-obra e equipamentos. Este espaço por sua vez, apesar de temporário, passa a ser determinante na obra, pois exerce atividade de apoio e execução, além do compromisso com a segurança e qualidade do empreendimento. De acordo com Fonseca (2013), a Norma Regulamentadora 18 define o canteiro de obras como sendo uma área fixa e temporária responsável pela execução das 
atividades, ou seja, uma "fábrica móvel".

Já a etapa de planejamento em uma obra é determinante na escolha dos materiais de maneira que é necessário estabelecer alguns critérios como melhor seleção de recursos com baixa energia incorporada, a utilização de materiais certificados, maximizar a utilização de materiais com elevado potencial de reutilização e reciclagem de material (Mateus \& Bragança, 2006), além, é claro, da redução de desperdício e retrabalho.

Logo, percebe-se que a construção civil está em busca de eficiência produtiva e sustentabilidade, forçando os gestores a melhorarem o planejamento e controle de seus empreendimentos, de modo a evitar gastos e cumprir prazos (Rocha Neto, 2010), assim como o cumprimento da legislação de segurança do trabalho e normativas técnicas.

Neste sentido, o canteiro de obras precisa ser pensado em prol dos colaboradores em termos de acesso aos materiais de consumo, vestiários, equipamentos, entrada e saída de veículos, entre outras estruturas. Não obstante é de grande importância a percepção correta dos recursos empregados, o acompanhamento da obra bem como equipe técnica multidisciplinar.

O Canteiro precisa ser pensado como engrenagem crucial em uma obra, sendo responsável por todo o suprimento e distribuição física de recursos, sejam: pessoas, materiais e máquinas/equipamentos. Já afirmava Ribeiro (2006) ao destacar que os tradicionais sistemas de gestão não alcançavam níveis satisfatórios, exigindo reformulações e modernizações, o que é comum até os dias atuais. Isto, atualmente, é percebido nos canteiros de obras como espaço planejado e projetado que passa a ser determinante em qualquer obra de maneira a otimizar espaço e maior eficiência na alocação de recursos. A necessidade de máxima eficiência, portanto, vem gerando alterações nos processos tecnológicos e administrativos das grandes empresas.

Uma gestão eficaz pode trazer benefícios significativos para a empresa quanto aos seus objetivos estratégicos, e também promover maior agilidade nas operações e melhoria contínua da qualidade e dos preços dos materiais adquiridos (Palacios, 1995). Assim com um melhor planejamento é possível reduzir investimentos, otimizar o tempo nas operações, dar mais agilidade na execução de atividade entre outros aspectos. Tendo isso em vista, acredita-se que as empresas deveriam focar em reorganizar processos, otimizar suas estratégias produtivas e racionalizar suas atividades.

O objetivo deste trabalho é identificar quais as boas práticas e ferramentas utilizadas nos canteiros de obras no Brasil considerando a percepção dos profissionais da construção civil, empreiteiros e demais empresas ligadas ao setor. Assim os objetivos podem ser desdobrados em objetivos específicos tais como: entender se as empresas desenvolvem ou não o projeto e planejamento de canteiro, elencar as boas práticas aplicadas nas obras, identificar as ferramentas inseridas nos canteiros de obras e avaliar os resultados da adoção destas práticas. Como rota metodológica o trabalho foi fundamentado em pesquisas bibliográficas por meio de trabalhos acadêmicos, visando um aprofundamento do tema, bem como uma análise qualitativa, por meio de pesquisa de campo que identifica a opinião de profissionais sobre as práticas e ferramentas adotadas.

\section{Metodologia}

A pesquisa apresenta um caráter exploratório (Gil, 2008), na qual, por meio de uma revisão bibliográfica via internet, livros didáticos, dissertações, teses, trabalhos publicados e revistas científicas nacionais e internacionais, foi possível fundamentar o trabalho.

Para o desenvolvimento do artigo foi realizada uma pesquisa de campo que assumiu uma característica hipotéticodedutiva (Marconi \& Lakatos, 2006). Desta forma, a coleta de dados foi realizada através de questionário online, Google Forms.

A partir de uma população de 80.684 empresas da construção civil, incluindo empresas no ramo imobiliários, reformas, obras de infraestrutura e serviços (Pesquisa Anual da Indústria da Construção - PAIC-IBGE - 2018), o questionário foi enviado para aproximadamente 15.000 profissionais presentes em grupos técnicos virtuais durante os meses de janeiro e 
fevereiro de 2021.

O questionário foi composto de 22 questões, sendo 8 com objetivo de mapear o perfil sociodemográfico e 14 perguntas para identificar os aspectos gerais acerca das ferramentas e as boas práticas aplicadas aos canteiros de obra. $\mathrm{O}$ questionário foi dividido em duas partes: perfil (local, formação, idade, cargo, setor e experiência), na etapa de aspectos gerais procurou identificar a área e o tipo de profissional, e por fim no mapeamento das experiências foi possível identificar práticas desenvolvidas nas obras, quer seja por meio de métodos/técnicas, equipamentos e sistemas (software). O mesmo foi validado por 3 experts ( 2 professores e 1 profissional da área) sendo posteriormente realizado um teste piloto com 3 respondentes para verificar possíveis problemas, assim realizando os ajustes no conteúdo.

A amostragem foi calculada por meio da equação (1):

$$
\frac{\frac{z^{2} \times p(1-p)}{e^{2}}}{1+\left(\frac{z^{2} \times p(1-p)}{e^{2} N}\right)}
$$

Sendo;

$\mathrm{z}=$ grau de confiança em desvios padrões $=95 \%$

$\mathrm{e}=$ margem de erro escolhida $=10 \%$

$\mathrm{N}=$ tamanho da população $=80.684$ (PAIC/IBGE, 2018);

$\mathrm{p}=$ na calculadora, ela é uma constante igual a 0,5

Considerando todas as variáveis no cálculo da amostra seriam necessários minimamente 96 respostas, porém, foram captadas 120 respostas.

\section{Resultados e Discussão}

Através das respostas recebidas acerca do planejamento, projeto e ferramentas utilizadas nos canteiros de obras, presentes na Indústria da Construção Civil Brasileira, foi possível identificar o entendimento e opinião por parte dos profissionais sobre o assunto, práticas adotadas e disseminação entre as empresas do setor.

Primeiramente, os entrevistados foram questionados quanto ao estado que trabalham; faixa etária; formação acadêmica; cargo atual; setor de atuação dentro de sua organização; tamanho da empresa e segmento de atuação que trabalha atualmente. Ou seja, nesta fase da pesquisa, foi elaborada uma análise do perfil profissional dos entrevistados.

Inicialmente, houve o questionamento sobre o perfil profissional de cada respondente, indagando qual a localização (estado) que o profissional trabalha atualmente, além do tamanho (porte empresarial, conforme o IBGE) da organização do mesmo e segmento de atuação, conforme indicado nos gráficos 1,2 e 3, a seguir. 
Gráfico 1 - Localização da Empresa (estado onde atua).
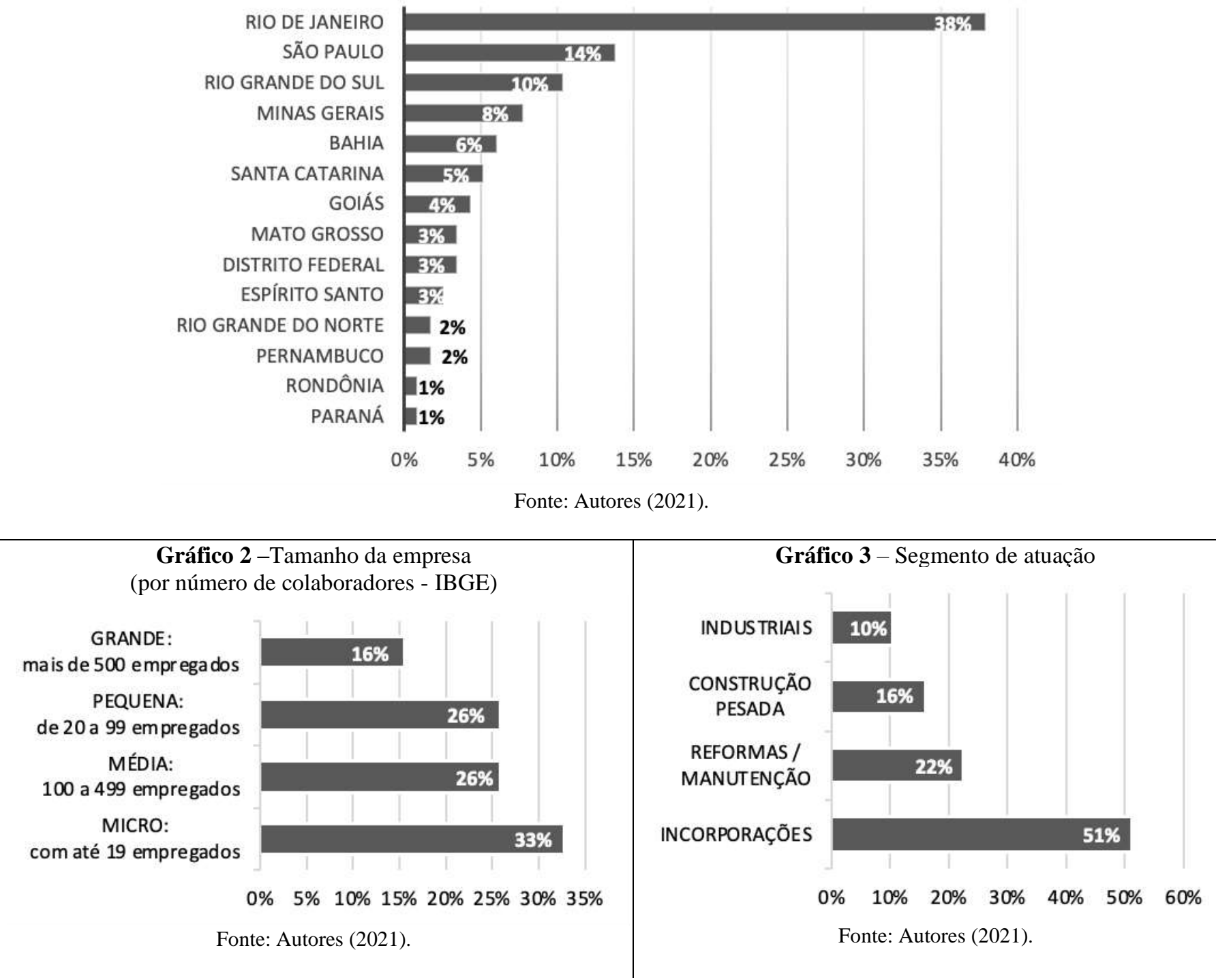

Das 27 unidades federativas, participaram 14, ou seja, mais de 50\% dos estados. A pesquisa se concentrou nas regiões sul e sudeste com 79\% dos entrevistados. A região nordeste participou com 9\%, a região centro-oeste com $8 \%$. E a menor participação, com 1\%, ficou a região norte, conforme Gráfico 1. Este formato se equilibra com a representação do PIB Brasil por região, também liderada pelas regiões Sul e Sudeste com 70,2\% (IBEG, 2019).

Quando questionados sobre o porte da empresa que atuam, conclui-se que mais da metade dos entrevistados (59\%) trabalha em empresas pequenas ou micro. Ou seja, empresas pouco profissionalizada e com estruturas ainda familiares e com muitos concorrentes no mercado, conforme Gráfico 2. Percebe-se um foco da pesquisa em obras prediais, pois somando o percentual de respostas em obras de incorporações com $51 \%$ e reformas/manutenção com $22 \%$, chegamos a total de $73 \%$ dos entrevistados, conforme Gráfico 3.

Posteriormente, os profissionais foram questionados sobre requisitos profissionais, tais como: Faixa Etária, Formação, Cargo, Setor e Tempo de Experiência, conforme indicado nos Gráficos seguintes (4, 5, 6, 7 e 8): 

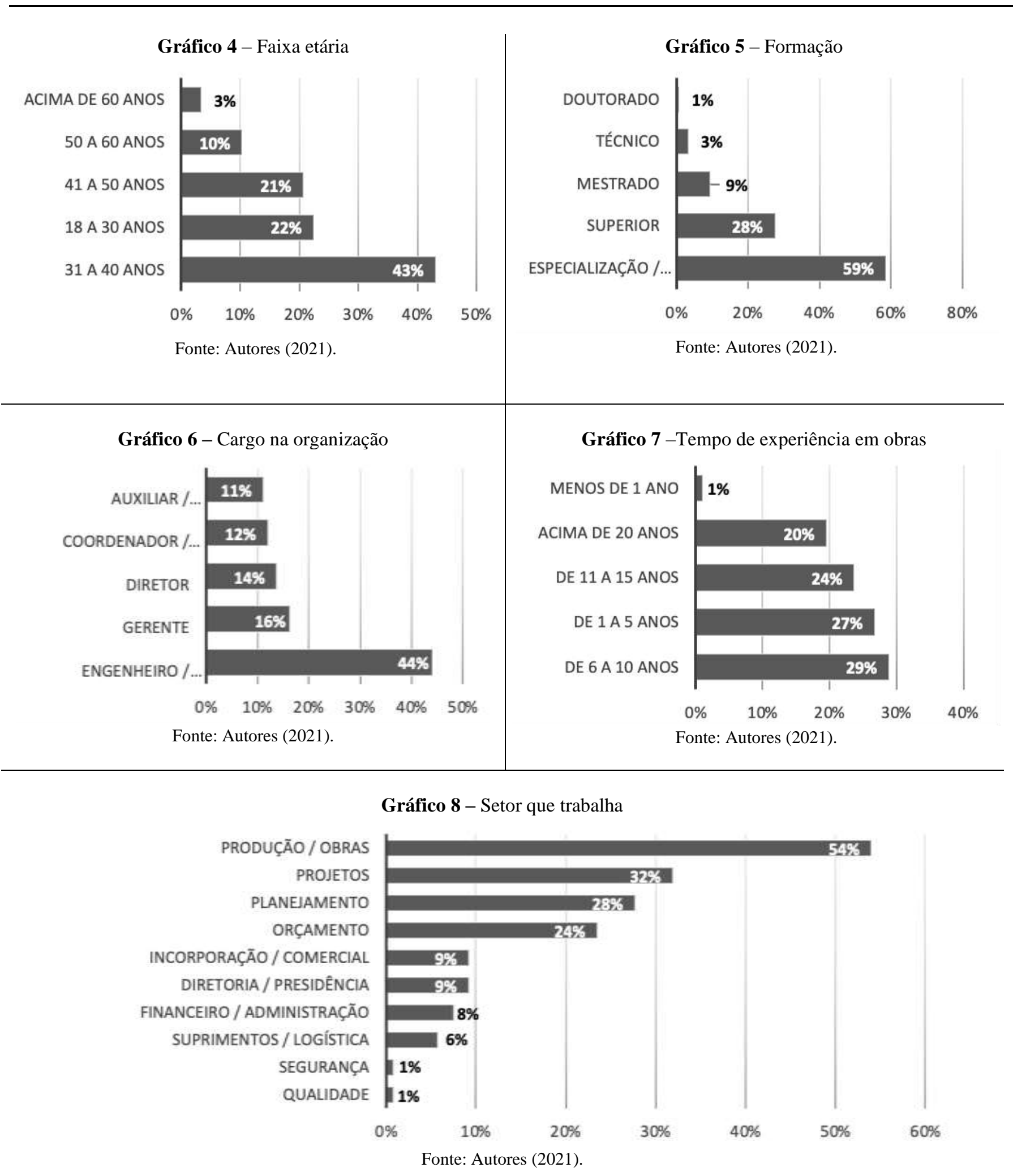

O Gráfico 4, reflete a realidade expressa pela divisão da faixa etária do quadro funcional, em que $43 \%$ do público possui entre 31 e 40 anos, ou seja, público ainda jovem, que se somados aos respondentes entre 18 e 30 anos (22\%) chegamos a um total de $65 \%$, praticamente $2 / 3$ da pesquisa.

Quanto a formação (Gráfico 5), 87\% dos entrevistados possuem algum tipo de especialização ou pós-graduação. Somando os doutores e mestres, chega-se a um total de $97 \%$ dos entrevistados. Nota-se um público com elevado conhecimento acadêmico, porém jovem, ainda mais levando em consideração que apenas $6,38 \%$ da população bruta brasileira são pós- 
graduados (SIDRA / IBGE, 2020).

Percebe-se que a maior parte dos entrevistados possui cargo de liderança. Ao somar engenheiros, coordenadores, gerentes e diretores (Gráfico 6), se tem $86 \%$ do total de respostas, ou seja, com tomada de decisão no tocante a gestão da obra.

Quando indagados sobre o tempo de experiência em obras (Gráfico 7), percebe-se que a maior parte dos profissionais (74\%) podem ser considerados como profissionais plenos ou sêniores, ou seja, acima de 6 anos de experiência. Apenas 27\% dos profissionais possuem experiência igual ou abaixo de 5 anos.

Foi possível notar no Gráfico 8, que existe uma boa distribuição dos profissionais nos diversos setores das organizações, onde praticamente metade participa da fase de desenvolvimento (projeto, planejamento e orçamento) e a outra parte, 54\%, na produção, no chamado "chão de fábrica". Os respondentes, nestes itens, puderam marcar mais de um setor, sendo assim percebe-se que alguns deles trabalham em vários setores ao mesmo tempo, atuando desde a fase de planejamento até entrega, passando, é claro, pela produção/obras. Isso pode contribuir para o desenvolvimento, inovação e criatividade na busca pela entrega de resultados.

Depois da análise das empresas e do perfil dos profissionais da construção, identificou-se as práticas adotadas, limitações, nível tecnológico entre outros pontos relacionados ao ambiente Canteiro de Obras.

Inicialmente, conforme mostra o Gráfico 9, verificou-se os resultados quanto aos quesitos que consomem mais tempo no canteiro de obras.

Gráfico 9 - Quais os 5 (cinco) itens que consomem mais tempo no seu canteiro de obras?

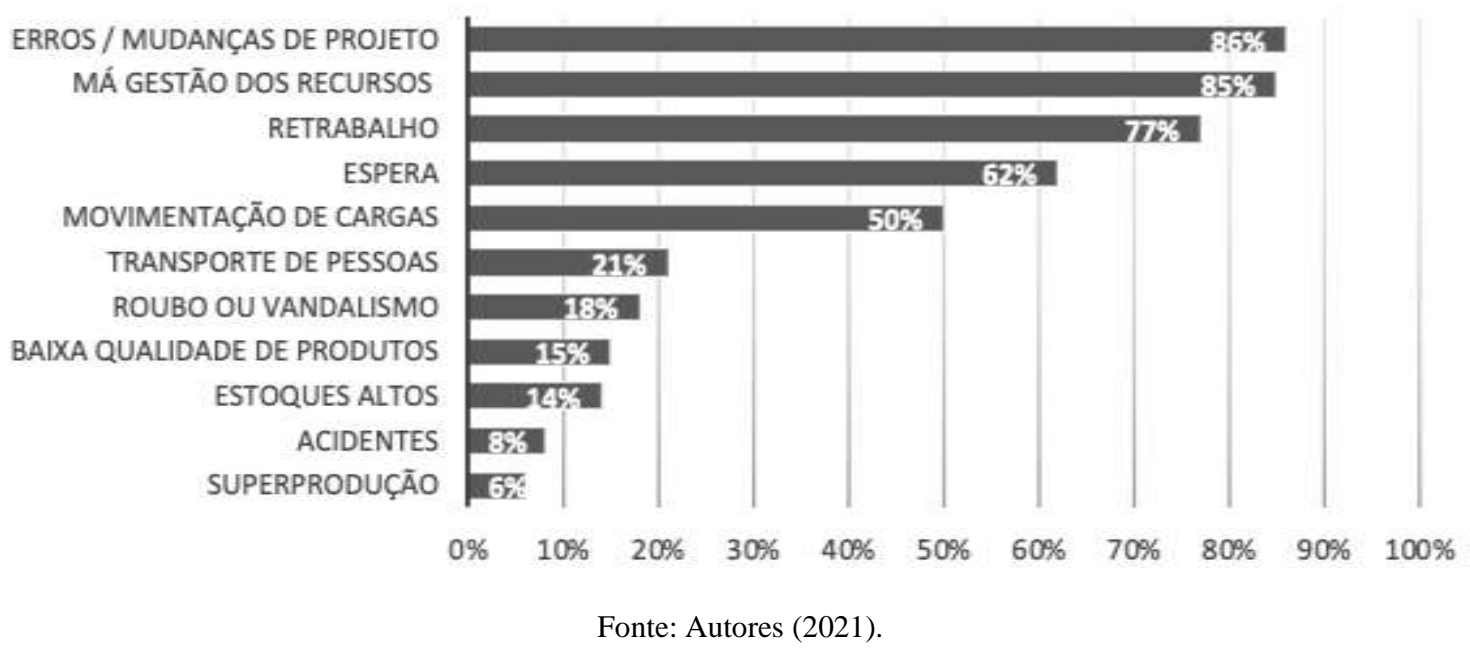

Os resultados apontam que erros de projetos e má gestão dos recursos foram citados mais vezes como os itens que mais consomem tempo com $85 \%$ e $86 \%$ respectivamente, seguidos por retrabalho, espera e movimentações de cargas com $77 \%, 62 \%$ e $50 \%$ das citações respondidas pelos entrevistados.

Viana et. al. (2012) consideram que estes tipos de perdas, anteriormente apontados, representam um percentual relativamente elevado nos custos da construção, devendo, portanto, ser tema de discussão objetivando a sua redução, podendo acontecer em qualquer fase do seu projeto, desde a concepção até a entrega, e são causadas principalmente por atividades que, uma vez não desenvolvidas na fase de planejamento, podem impactar diretamente no sucesso de uma obra no que tange as principais restrições: prazo, custo e qualidade.

Falcão, Brandstetter \& Amaral (2010), em pesquisa sobre diretrizes estratégicas para melhoria de eficiência logística em canteiro de obras, definem dois grandes fatores que interferem na produtividade de uma obra: a falta de material para a continuidade do trabalho e a transferência de trabalhadores para outros tipos de serviço. O Gráfico 10 apresenta os resultados 
quanto as atividades mais negligenciadas no canteiro de obra.

Gráfico 10 - Quais as 5 (cinco) atividades mais negligenciadas no canteiro de obras?

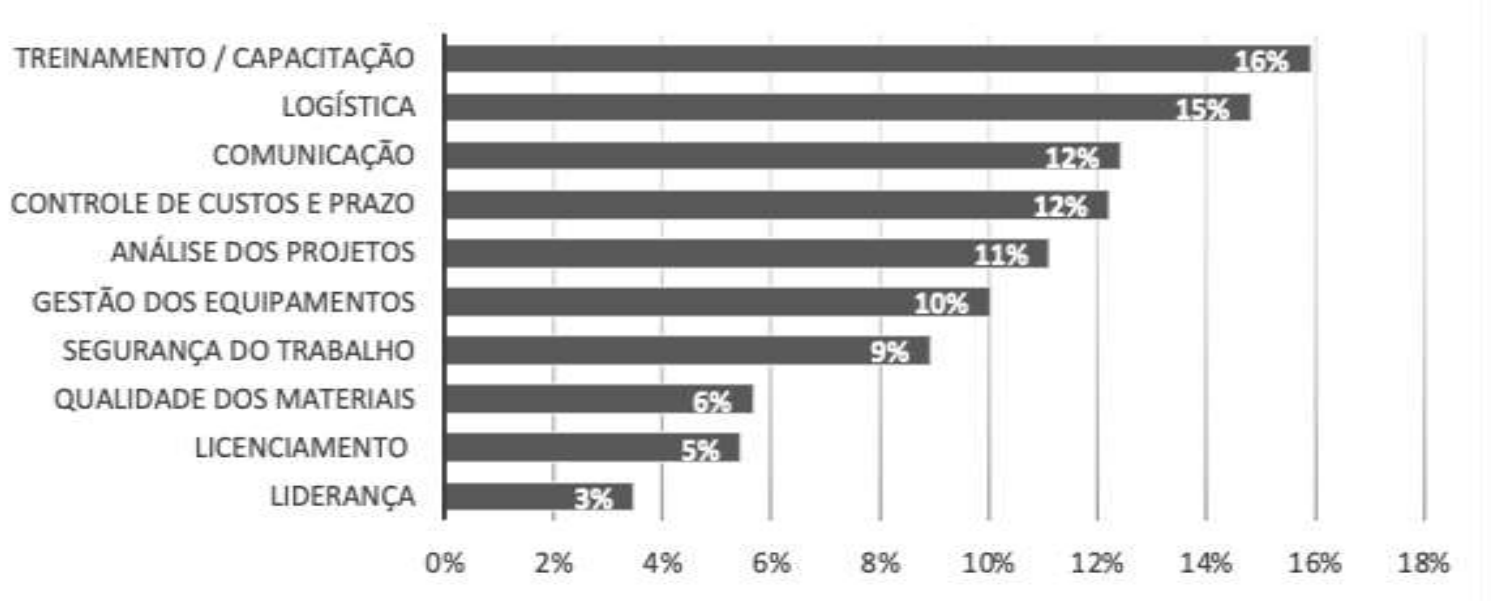

Fonte: Autores (2021).

Quando questionados sobre as atividades mais negligenciadas os entrevistados afirmaram em 16\% das respostas que são o treinamento e capacitação, enquanto $15 \%$ que a logística é uma área penalizada, seguido da comunicação e controle de custos e prazo com $12 \%$ cada um.

Pinho (2013), esclarece que os fatores que causam os desperdícios na construção civil estão associados a três categorias: seleção dos materiais (logística), liderança e controle do projeto. Em obras é muito comum acontecer mudanças de projeto pelos clientes, gerando retrabalhos e desperdícios.

A comunicação (insuficiente ou deficiente) é realmente um dos grandes vilões de todos os projetos, não somente na construção civil, sendo responsável pelo insucesso de 64\% dos projetos no mundo, conforme Project Management Institute Brasil (PMI-2014). O aspecto de liderança fica claro como fundamental neste sentido para a maior capacitação e melhor comunicação entre profissionais.

O Gráfico 11 apresenta os resultados sobre o questionamento relacionado ao Cálculo de Equipamentos para o canteiro de Obras.

Gráfico 11 - Você calcula a quantidade necessária de equipamentos levando em conta as cargas, ciclos de movimentação e prazos de execução:

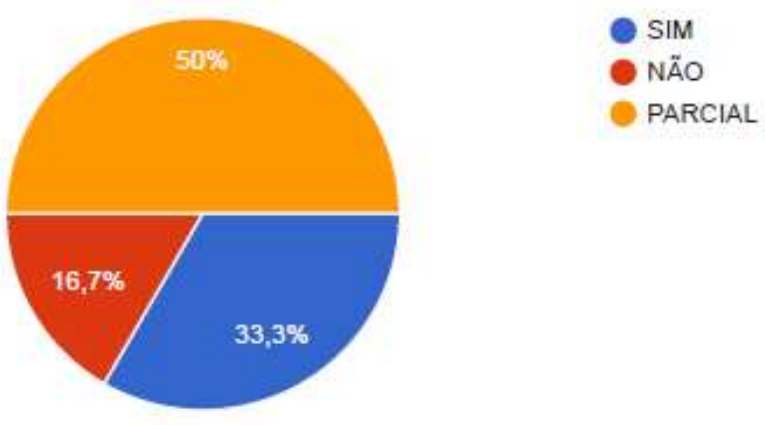

Fonte: Autores (2021).

Trata-se de um resultado preocupante, pois a falta de planejamento em termos de suprimento e logística, pode gerar inúmeros problemas quanto a movimentação, estoque e distribuição. Vieira (2020), já destacava que em um sistema 
construtivo as atividades de armazenagem, o processamento de materiais, a alocação de recursos humanos e informações são necessários para proporcionar a redução de custos e aumento da produtividade e do nível de serviço.

Os dados revelam que 50\% dos entrevistados dizem realizar este planejamento parcialmente. Deste mesmo grupo somente 33,3\% dizem realizar o devido planejamento. Isto está alinhado com Aguiar (2016), que destaca que a construção civil se trata de um "processo multidisciplinar aplicado nas obras, que visa garantir a aquisição, o armazenamento, o processamento e a disponibilização de recursos e materiais nas frentes de trabalho".

No gráfico 12, faz-se o questionamento aos entrevistados sobre a utilização de Check List na implantação dos requisitos relativos às NRs (Normas Regulamentadoras da Secretária do Trabalho do Governo Federal), principalmente a NR18, exigidos pela Secretaria do Trabalho do Governo Federal, obrigatório para todos os canteiros de obras.

Gráfico 12 - Você utiliza Check List para implantação dos requisitos relativos às NRs (normas regulamentadoras)?

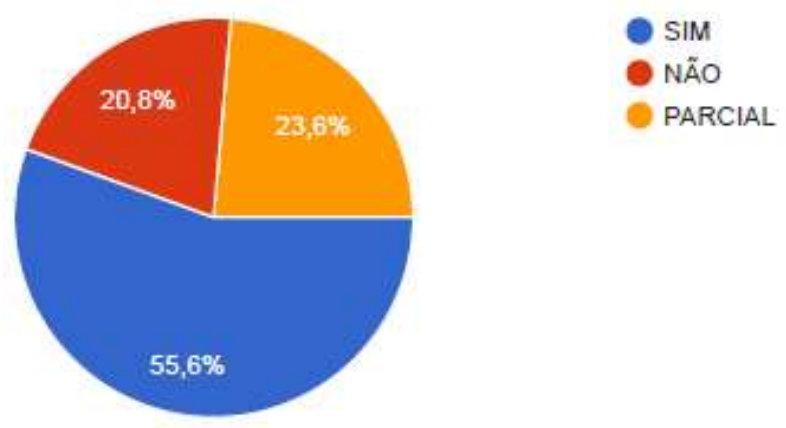

Fonte: Autores (2021).

Observa-se no Gráfico 12, que 55,6\% fazem uso de modelos de controle quanto ao cumprimento de requisitos normativos, 23,6\% em parte tratam este tema, mas o dado de alerta é que 20,8\% não fazem uso de qualquer método de controle para cumprimento da norma. Já no gráfico 13, consegue-se visualizar quais os itens relativos à "SEGURANÇA" são utilizados pelos profissionais.

Gráfico 13 - Quais itens relativos à "SEGURANÇA" você considera / utiliza em suas OBRAS?

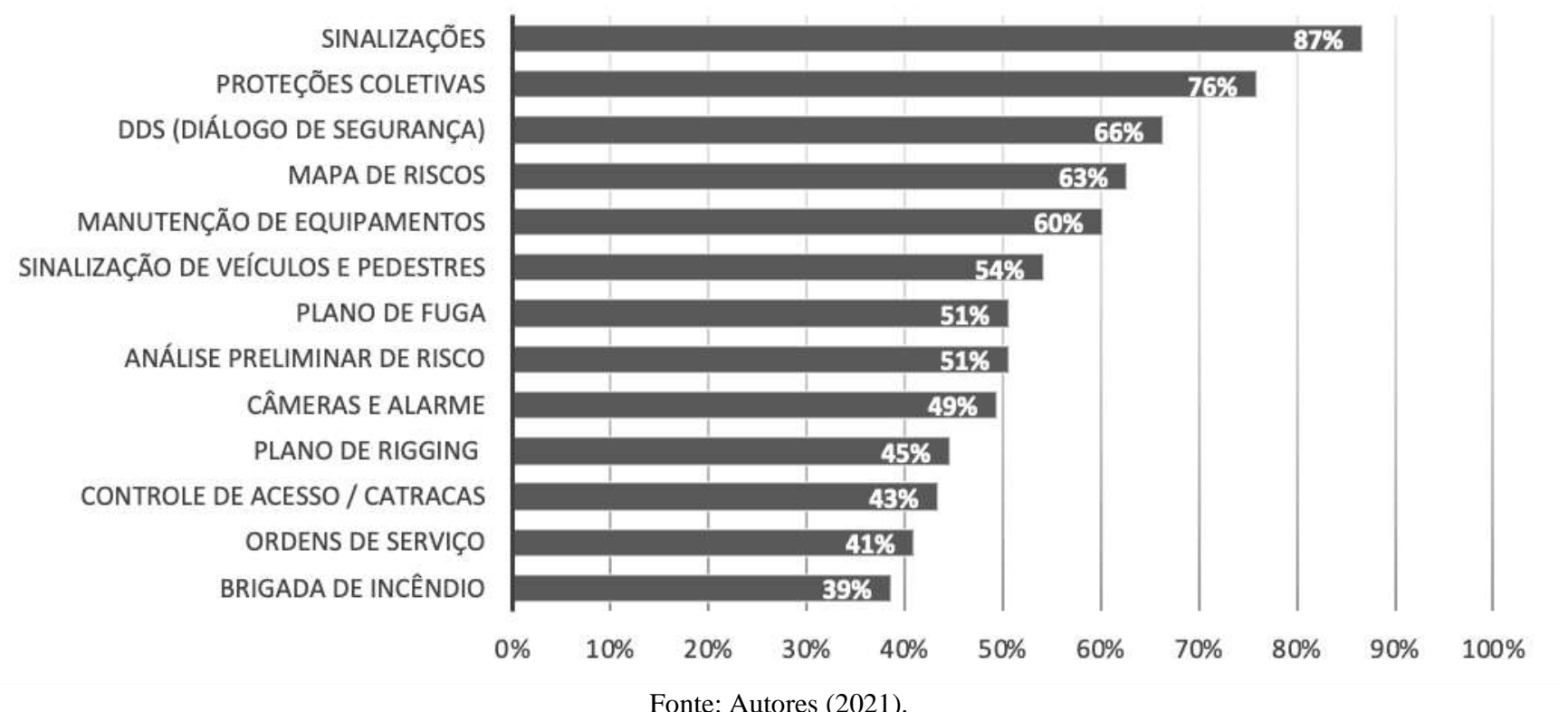


Agora, complementando o assunto Segurança no Canteiro, pode-se analisar os itens de segurança utilizados. Conforme o Gráfico 13, constatamos que $87 \%$ dos entrevistados afirmaram que fazem uso de dispositivos de alerta (sinalizações), outros 76\% priorizam as proteções coletivas e 66\% do Diálogo Diário de Segurança como forma de prevenir acidentes. Porém, apenas 39\% dos profissionais utilizam Brigada de Incêndio, e $41 \%$ de Ordem de Serviço, requisitos importantes e em alguns casos obrigatório, dependendo do tipo e tamanho de obra.

No Brasil, os acidentes ocorridos na indústria da construção brasileira, conforme as estatísticas anuais do Ministério da Previdência e Assistência Social (Anuário Estatístico de Acidentes de Trabalho - AEAT, 2017) giram em torno de 5,46\%, em relação ao total de acidentes, ou seja, com mais de 500 mil acidentes todos os anos.

Constata-se que, caso os requisitos mínimos das NRs fossem utilizados, somando a outras ferramentas de segurança, os indicadores poderiam ser bem menores, principalmente porque apenas $55,6 \%$ dos entrevistados utilizam plenamente os requisitos e aproximadamente metade utiliza a maior parte das ferramentas citadas.

A complexidade e o tempo de implementação, normalmente estão em descompasso com a obra, motivados pela falta de ações na fase de planejamento. Soma-se a isso uma fiscalização preventiva deficiente que pouco conhece o que precisa ser fiscalizado. O grande desafio é realmente conscientizar o maior número de empresas e profissionais, expandir o conhecimento e fazer entender que os custos em Segurança do Trabalho, além de serem investimento, garantem sustentabilidade e, muitas vezes, mais produtividade do trabalhador. (Vieira et al, 2020).

Agora, no Gráfico 14, pode-se analisar os resultados referentes as práticas logísticas.

Gráfico 14 - Quais boas práticas e ferramentas em "Logística" você utiliza no seu canteiro de obras?

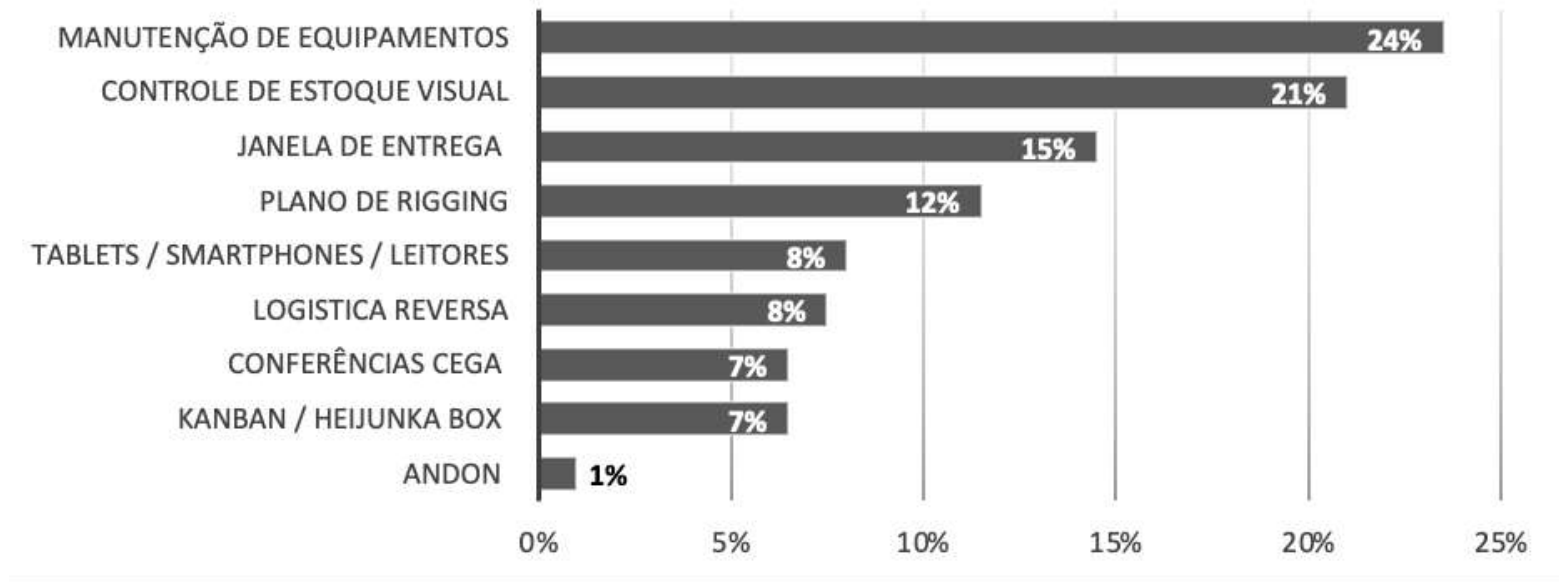

Fonte: Autores (2021).

Os resultados apontam que dentre as práticas logísticas, somente $24 \%$ dos profissionais fazem o trabalho de manutenção de equipamentos, $21 \%$ se utilização de Controle de Estoque Visual e 15\% como o uso de janela de entrega (horários para recebimento de materiais), ou seja, ainda sendo utilizada de forma muito incidida e pontual.

Para Serra (2001), cada tipo de canteiro de obras apresenta uma especificidade no que tange a transporte, movimentação, equipamentos e outros. Desta forma a logística passa a ser um diferencial na construção civil e tem como principal função melhorar a eficiência e eficácia dos processos proporcionando maior visibilidade a gestão sobretudo nos custos associados a organização.

Outro dado, é que apenas $8 \%$ fazem uso da sistemática de logística reversa e também $8 \%$ fazem uso de tecnologias com dispositivos, tais como: tablets, smartphones e leitores diversos. Essas tecnologias melhoram bastante as relações entre fornecedores e empresas, tornando possível interface na comunicação de dados, a ponto dos fornecedores controlarem on-line 
(tempo real) a necessidade do mercado, através do monitoramento dos estoques alinhado a uma gestão mais eficiente nos canteiros de obra (Sacilotti, 2010).

Porém, uma boa prática que vem sendo utilizada amplamente em outros tipos de indústrias como é o caso do "Kanban", vem sendo utilizada de forma muito branda nos Canteiros com apenas 7\% das respostas.

Schlindwein (2012) destaca que não se pode pensar em otimização dos recursos (produtividade), redução de custo, sem que não se pense em logística e tecnologia antes. Ou seja, o setor da Construção Civil incorporou estas atividades com objetivo de impulsionar crescimento, mas percebe-se que ainda há de se percorrer um longo caminho.

O Gráfico 15 apresenta os resultados quanto aos principais tipos de sistemas construtivos adotados pelos profissionais para as construções relativas ao Canteiro, tais como: escritório, refeitório, vestiários, almoxarifado etc.

Gráfico 15 - Quais os "Sistemas Construtivos" você utiliza nos seus canteiros de obras?

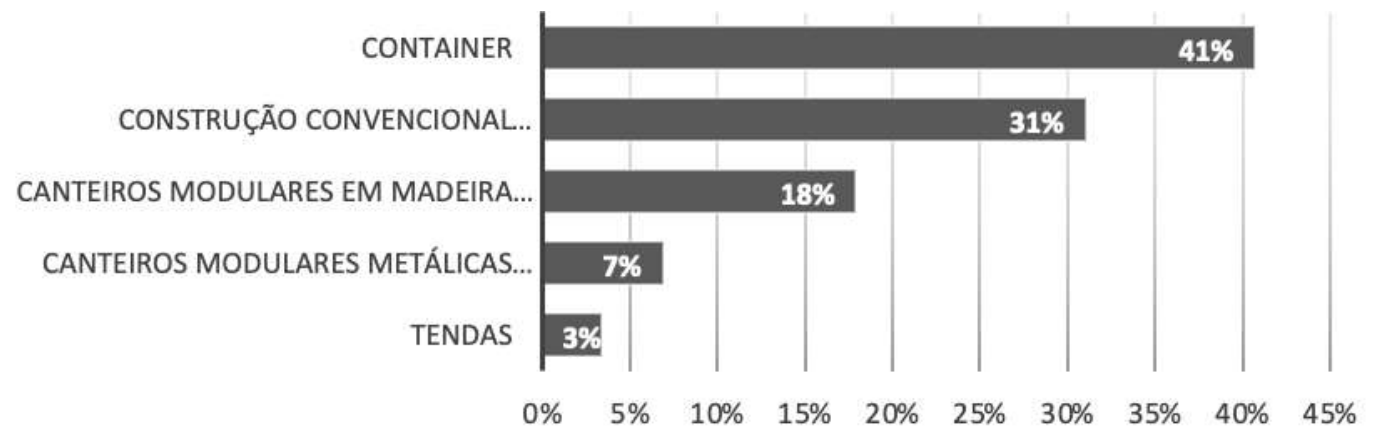

Fonte: Autores (2021).

Percebe-se que 40,7\% dos entrevistados pontuam que o uso de contêiner são os mais utilizados entre os métodos construtivos, seguido da construção convencional (31\%), o que impressiona pelos fatores negativos deste tipo de construção, principalmente, resíduos gerados, empregos de intensa mão de obra e prazo de construção. Somando os sistemas industrializados (containers, woodframe e drywall e steel frame) chega-se a quase $70 \%$ do total de resposta, mostrando uma boa evolução neste sentido.

Para Ferreira (1998), um canteiro de obras deve garantir a infraestrutura necessária para a produção do edifício, tendo os recursos disponíveis à medida que forem necessários. Além disso, esta organização deve considerar a complexidade e o dinamismo intrínsecos a um canteiro de obras. Um projeto eficiente de canteiro de obras, além de garantir a segurança dos trabalhadores, traz em seu bojo qualidades que refletem no desempenho total do empreendimento. Tecnologicamente falando, o Gráfico 16 apresenta os resultados referente às ferramentas utilizadas no canteiro de obras. 
Research, Society and Development, v. 10, n. 9, e55110918407, 2021

(CC BY 4.0) | ISSN 2525-3409 | DOI: http://dx.doi.org/10.33448/rsd-v10i9.18407

Gráfico 16 - Quais boas práticas e ferramentas "Tecnológicas" você utiliza no seu canteiro de obras?

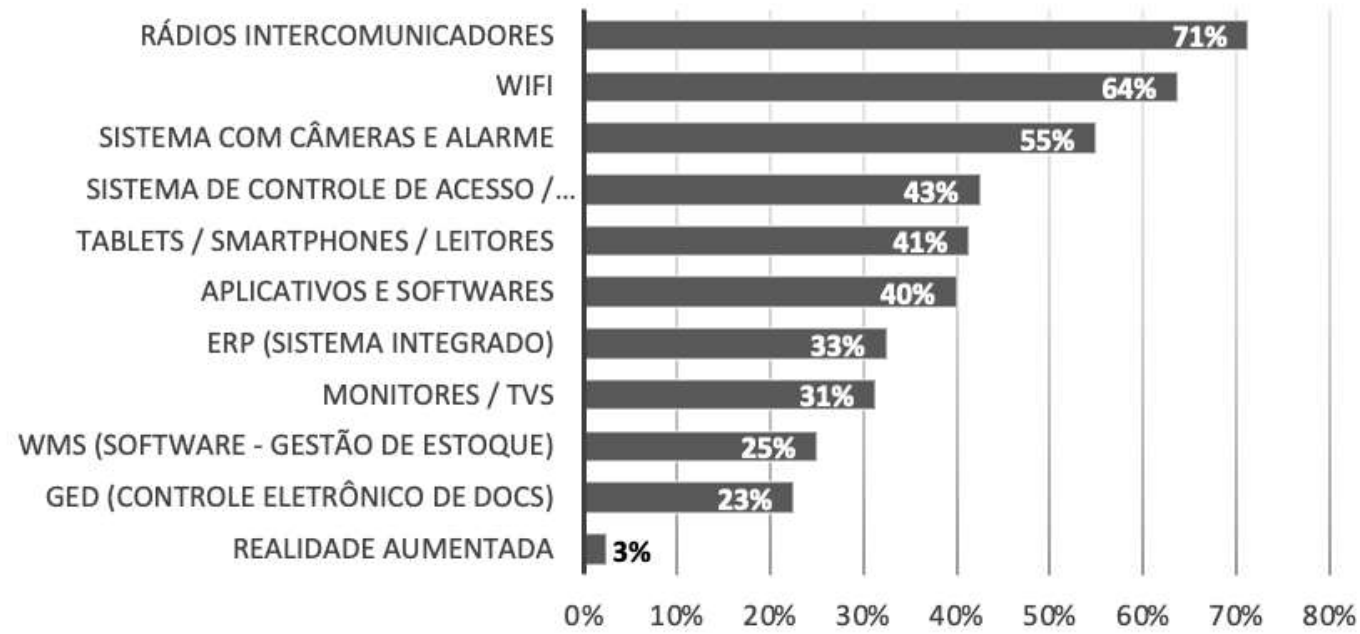

Fonte: Autores (2021).

Quando o assunto é relacionado aos sistemas tecnológicos utilizados no canteiro, $71 \%$ dos entrevistados responderam utilizar rádios intercomunicadores, 64\% utilização tecnologia Wifi, 55\% instalam sistemas de monitoramento, segurança e alarme, além de 43\% apenas usarem Controle de Acesso e 41\% Dispositivos como Tablets e Smartphones, denotando assim, que ainda temos bastante a evoluir o que pode ser comprovado pela pesquisa dos quais setores são mais digitais (McKinsey Global Institute, 2016). Agora, no Gráfico 17 foram apresentados os resultados sobre as práticas sustentáveis adotadas nas construções. 
Gráfico 17 - Quais boas práticas e ferramentas "Sustentáveis" você utiliza no seu canteiro de obras?

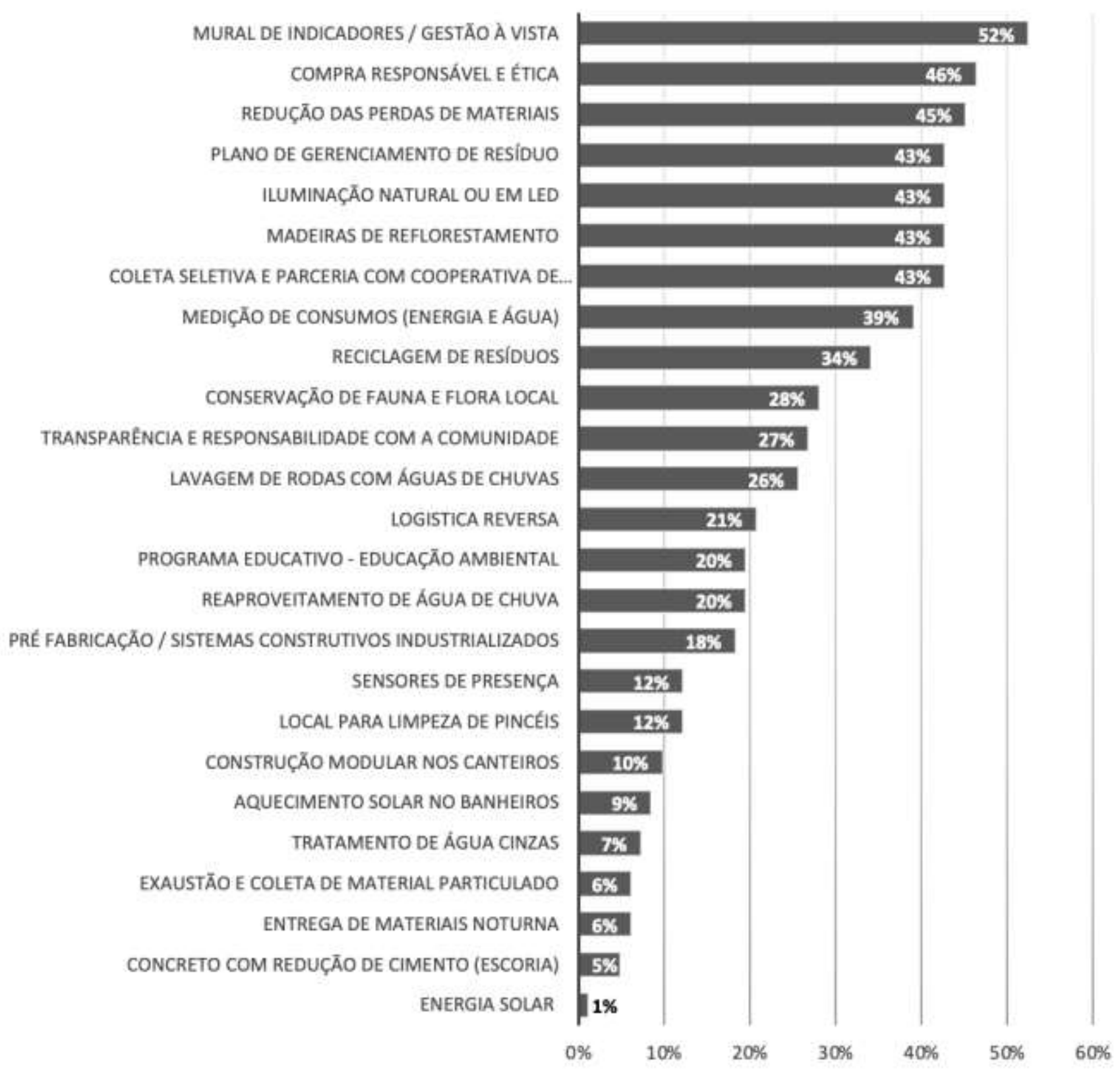

Fonte: Autores (2021).

Os resultados apontam que 52\% dos entrevistados implementam em suas atividades a gestão visual com murais de indicadores, já $46 \%$ fazem compras responsáveis e possuem premissas de ética e governança, além de $45 \%$ que dizem buscar a redução de perda de materiais e possuem sistemas de segurança contra furtos. Percebe-se, porém, que outras atividades, foram bem menos desenvolvidas tais como: logística reversa, reaproveitamento de água, aquecimento e energia solar, concretos com menos uso de cimento, pela necessidade maior de investimento para implantação e pelo desconhecimento destas práticas e sistemas.

Sabe-se que a Indústria da Construção é um dos grandes consumidores de recursos naturais (Bohnenberger et al., 2018), seja pela geração de uma enorme quantidade de resíduos ou pela operação de alto custo dos empreendimentos pós-obra. O mercado ainda aponta para uma maior necessidade de reaproveitamento e diminuição em termos de geração (Li-Yashuai, 2013), sendo que estudos recentes demonstram que os resíduos da construção civil têm um elevado potencial de reciclagem 
(Paz e Lafayette, 2016).

Agora, conforme o Gráfico 18, apresenta-se os resultados inerentes aos métodos de trabalho alinhados a gestão de pessoas.

Gráfico 18 - Quais boas práticas e ferramentas em "Gestão de Pessoas" você utiliza no seu canteiro de obras?

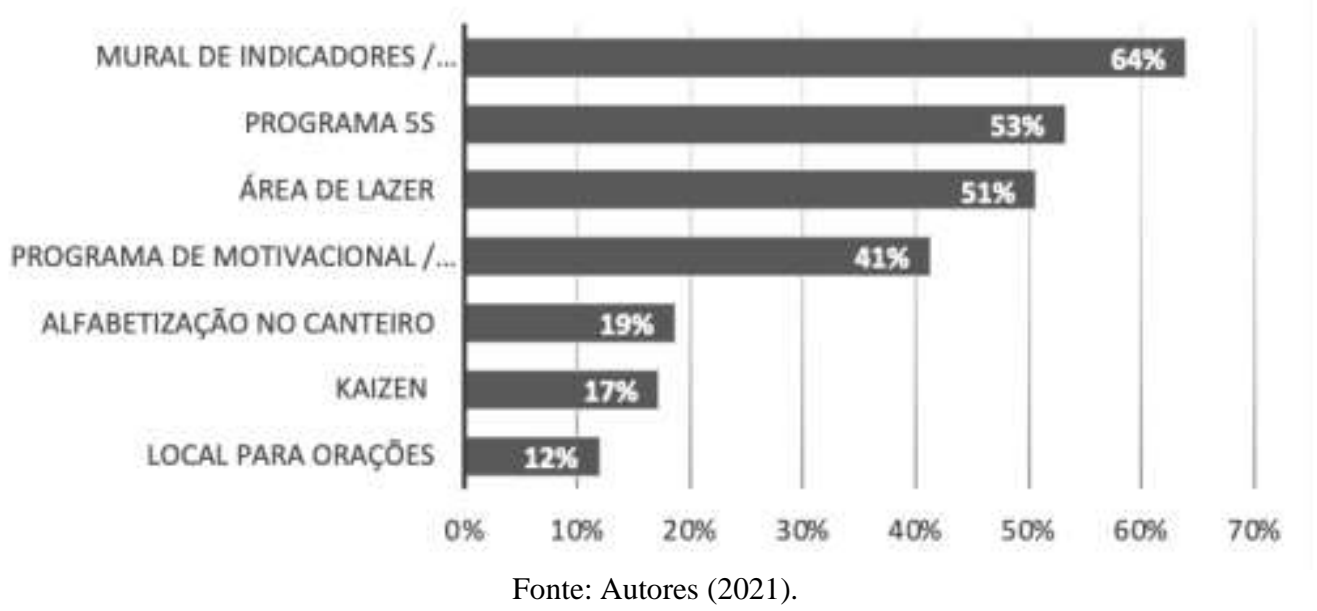

Os resultados constataram que $64 \%$ utilizam entre os instrumentos relacionados à gestão de pessoas o mural de indicadores, já 53\% têm implementado nos canteiros o programa 5S (Programa para Organização, Limpeza e Disciplina no Canteiro) outros 51\% têm áreas de lazer. Infelizmente os Programas de Alfabetização e Motivacional tiveram baixos resultados com $17 \%$ e $41 \%$, respectivamente, mostrando o baixo investimento em ações de capacitação.

Neste sentido, fomentar a conscientização e um treinamento de trabalhadores do canteiro de obras passa a ser determinante, visando a adoção de boas práticas dentro dos Canteiros. A linguagem deve ser de fácil compreensão e os pontos principais enfocados no treinamento devem se fundamentar na realização de um diagnóstico dos principais problemas que sistematicamente ocorrem nas obras (Lima, Oliveira, e Martins 2021).

Como foco deste trabalho, pode-se constatar no Gráfico 19, se o Planejamento e Projeto de Canteiro são desenvolvidos, ou não, pelos profissionais da construção civil. 
Gráfico 19 - Você já desenvolveu Planejamento e Projeto de Canteiro de suas obras?

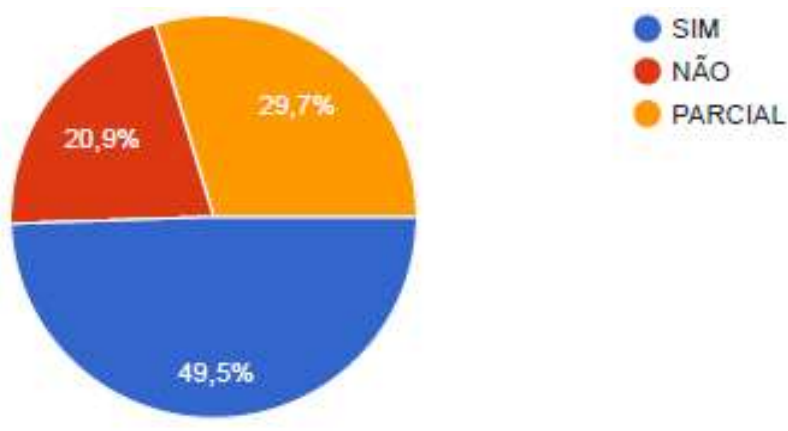

Fonte: Autores (2021).

Verifica-se, um triste indicador (conforme o Gráfico 19) onde praticamente metade dos profissionais do mercado $(49,5 \%)$ não fazem uso do Projeto e Planejamento de Canteiro. Somando a fatia que utilizam de forma parcial, chegamos a quase $80 \%$ dos profissionais, ou seja, a grande maioria do mercado trabalha de forma empírica, sem método e padrão, para o desenvolvimento de seus Canteiros, ou melhor, de suas "Fábricas", gerando assim o improviso e desperdício, trabalhando sem planejamento na base da "tentativa e erro".

Pinho (2013), destaca que estas situações geram perdas que não podem ser consideradas desprezíveis e diante de um mercado competitivo, com clientes cada vez mais exigentes, as empresas têm que, necessariamente, reduzir seus custos de produção, diminuindo os desperdícios, melhorando e aproveitando todos os recursos disponíveis. Complementando, no gráfico 20, consegue-se compreender quais os principais motivos para a falta de planejamento e projeto de canteiro.

Gráfico 20 - Quais os 5 (cinco) principais motivos da falta de planejamento e projeto de canteiro?

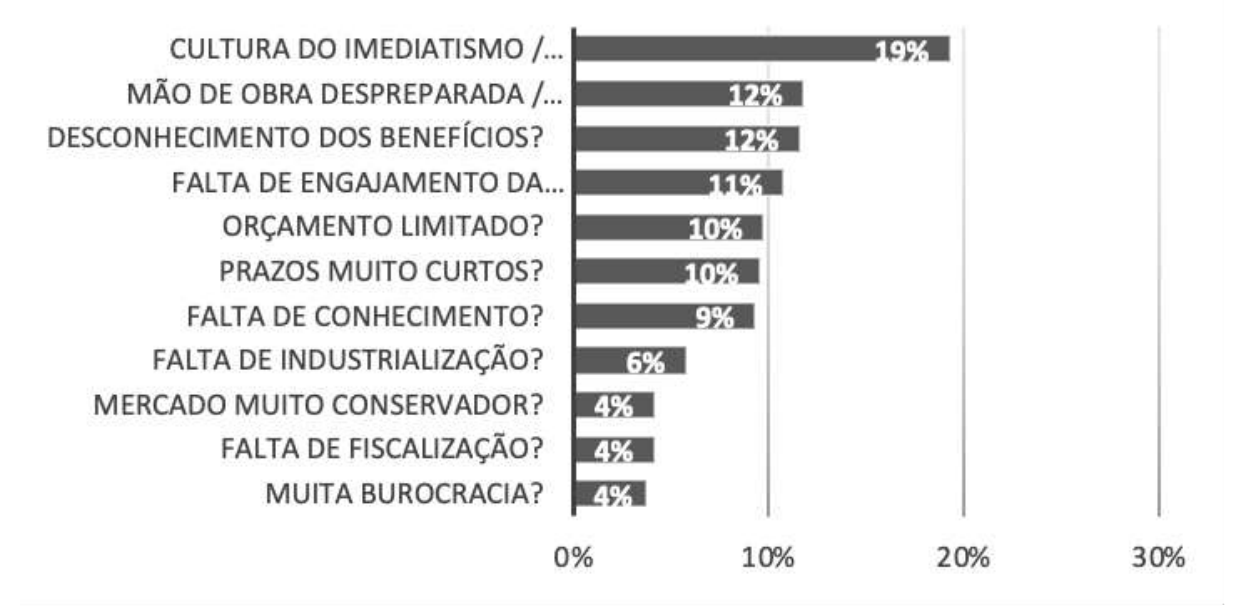

Fonte: Autores (2021).

A partir do Gráfico 20, consegue-se confirmar as principais causas para o não desenvolvimento do Planejamento e Projeto de Canteiro, onde a cultura do imediatismo e improviso lideram com 19\%, seguidos de 12\% para a Mão de Obra desqualificada, junto com o desconhecimento dos benefícios que o planejamento pode trazer. A falta de engajamento da liderança e o orçamento limitado também estão entre os principais motivos como $11 \%$ e $10 \%$ das respostas, respectivamente.

Corroborando com esta afirmação, Santos e Santos (2017), coloca que é possível considerar diversos problemas causados pela falta de planejamento, dentre elas: o improviso, que ocorre normalmente quando uma atividade se inicia sem que todos os recursos estejam disponíveis; a falta de terminalidade, quando se realizar uma tarefa e os recursos são retirados sem que a atividade tenha sido terminada; e o retrabalho, oriundo de mão de obra desqualificada. 
Percebe-se novamente que a fase do planejamento tem fundamental importância, neste caso com o desenvolvimento de padronização de processos e liderança. Agora no gráfico 21, a seguir, pode-se entender a avaliação dos profissionais quanto a importância do Projeto e Planejamento de Canteiro e se o mesmo pode trazer resultado e aumentar a taxa de sucesso das obras.

Gráfico 21 - Como você avalia a importância do Planejamento e Projeto de Canteiro para trazer resultado e aumentar a taxa de sucesso das obras?

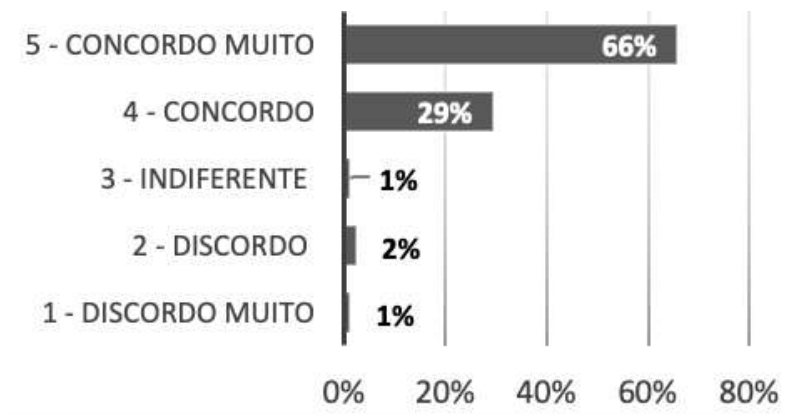

Fonte: Autores (2021).

Quando questionados sobre a importância do Planejamento e Projeto de Canteiro (Gráfico 21), observa-se que 95\% dos profissionais, "concordam" ou "concordam muito" que a prática pode gerar resultados e aumentar a taxa de sucesso dos empreendimentos da construção civil. Porém, não executam como retratado no Gráfico 19, destacando aí um grande paradigma, respondido no gráfico 20, onde o improviso e a cultura imediatista imperam como principais causas. Por fim, no Gráfico 22, a seguir, pode-se entender quais os benefícios gerados pelo desenvolvimento do Projeto e Planejamento de Canteiro.

Gráfico 22 - Quais os benefícios que o Projeto e Planejamento de Canteiro pode gerar?

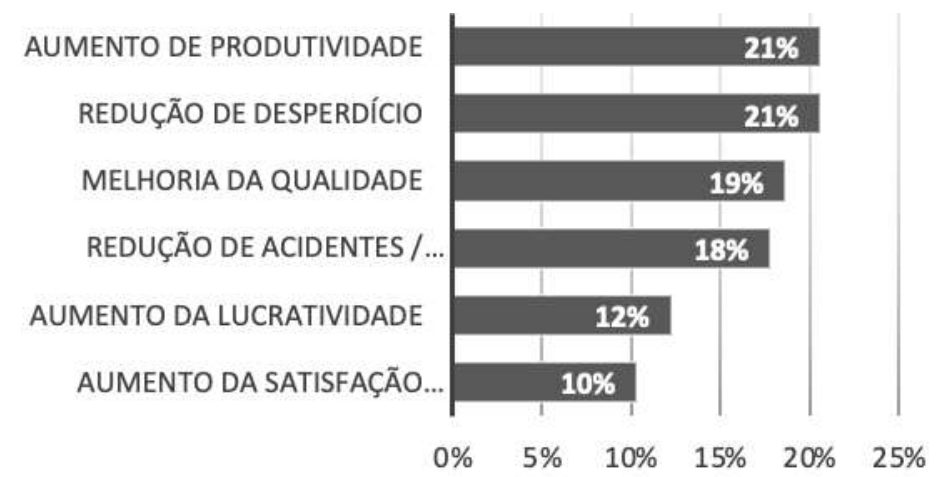

Fonte: Autores (2021).

Quando questionados sobre os benefícios de um bom Planejamento e Projeto de Canteiro (Gráfico 22) os entrevistados responderam que a redução do desperdício e o aumento de produtividade assumem a importância nos resultados com $21 \%$ das respostas cada. Outras $19 \%$ das respostas disseram que pode melhorar a qualidade nas obras e $18 \%$ consideram reduzir o índice de acidentes nos Canteiros. Ou seja, na percepção dos profissionais os resultados mais importantes estão relacionados ao Aumento de Produtividade, Qualidade e Redução de Desperdício.

Oliveira (2001), em seu estudo sobre a influência dos projetos para produção e de canteiro na construção propõe que um sistema logístico bem implantado e gerenciado pode reduzir o remanuseio, a movimentação e as perdas de materiais. Dessa 
forma o Canteiro torna-se mais produtivo, reduzindo o risco de acidentes, trazendo o aumento da motivação dos operários e proporcionando maior competitividade à empresa.

\section{Conclusão}

A presente pesquisa teve uma abrangência nacional (mais 50\% dos estados), como foco nas regiões de maior PIB (sul e sudeste), além disso, o perfil dos respondentes foi concentrado em profissionais que exercem liderança gerencial, em sua maioria com idade até 40 anos e com muita experiência em construção (74\% acima de 6 anos), além de elevado grau de conhecimento e capacitação, trabalhando em diversos setores de suas organizações, desde a fase de planejamento até entrega final, mas principalmente no "chão de fábrica" (canteiros de obras). Além disso, a maior parte dos profissionais que responderam à pesquisa, trabalham em construções prediais e em pequenas ou microempresas.

Ficou claro na pesquisa que muitos profissionais trabalham com falta de recursos (humanos e financeiros), possuem prazos muito curtos para a fase de planejamento, além é claro, do desconhecimento dos potenciais. Resultado de limitação ou falta de incentivo pelas suas lideranças. Vale colocar também a negligência, pois muitos subestimam tal fase.

Foi evidenciado a carência em treinamento, capacitação dos profissionais. A maior parte deles não desenvolvem o Projeto e Planejamento de Canteiro e ignora ou não tem conhecimento legal sobre as exigências mínimas para as instalações. Além disso, não calculam a quantidade de equipamentos necessária, nem muito menos se preocupa com as etapas logísticas, tais como: descarregamento, armazenamento, estoque e expedição.

A pesquisa explicou também que isso se deve a cultura do imediatismo, a falta de planejamento e pressão pela etapa de produção. Vale colocar que existe um mercado constituído em sua maior parte por pequenas e microempresas, como baixo nível de profissionalização somado a falta de engajamento e liderança de seus gestores, justificada pela mentalidade do improviso.

Do ponto de vista dos objetivos do trabalho foi possível verificar a falta de adoção de diretrizes e metodologias próprias e eficazes para o desenvolvimento do projeto e planejamento de canteiro, principalmente pela falta de atitude em desenvolvê-lo, por falta de tempo, recursos ou falta de exigência pela organização.

Mesmo assim, constatou-se que boas práticas nos canteiros vêm sendo utilizadas, desde o uso de gestão à vista até a aplicação por exemplo, de sistemas construtivos mais modernos como módulos metálicos, além de tecnologias como: BIM, WMS, aplicativos via Smartphones, Dispositivos, Rede Wifi, ERPs (Sistemas Integrados), GEDs (Gerenciadores Eletrônicos de Documentos), entre outros. Ou seja, muitos avanços vêm sendo desenvolvidos, com uso de ferramentas e boas práticas sustentáveis e tecnológicas, mas ainda se percebe um grande potencial de crescimento.

Uma gestão eficaz pode trazer benefícios significativos para a empresa quanto aos seus objetivos estratégicos, e promover maior agilidade nas operações e melhoria contínua da qualidade e dos preços dos materiais adquiridos. A importância dos canteiros é sabida pela maioria. Porém, a falta de cultura e gestão da cadeira produtiva de forma integrada precisa ser pensada como engrenagem crucial em uma obra, sendo responsável por todo o suprimento e distribuição física de recursos sejam eles humanos, materiais e máquinas/equipamentos.

Por fim, ficou claro que os profissionais entendem a importância do Projeto e Planejamento de Canteiro, mas não o fazem, por falta de liderança, motivação, recursos e principalmente cultura. Inclusive entendem que com o Projeto e Planejamento de Canteiro, pode-se aumentar a produtividade, qualidade e reduzir o desperdício, porém, a menor parte entende que o mesmo pode gerar maior lucratividade a organização e maior satisfação aos clientes finais, sem falar o ponto mais importante, a integridade dos profissionais e os requisitos legais relacionados a Segurança do Trabalho. 
Para Trabalhos futuros, recomenda-se um estudo de caso aplicado buscando a implantação dos requisitos desta pesquisa e, o desenvolvimento de estudo sobre tecnologias aplicadas ao canteiro de obras, ou seja, buscando entender qual nível de digitalização do Canteiro e seu futuro, mais conhecido e amplamente discutido como Canteiro 4.0.

\section{Referências}

Aguiar, g. S. G. (2016). Inovação em logística de Canteiro de obras na construção de edifícios. Dissertação de Mestrado. Universidade de São Paulo. São Paulo

Arantes, 1. C. (2008). Construção Sustentável: Oportunidades de negócio para a empresa Bautec Construções \& Incorporações Ltda. Complexo de Ensino Superior de Santa Catarina/CESUSC. Monografia (Graduação em Administração)

Barbosa, m. T. (2011). Concreto Ecológico. Universidade Federal de Juiz de Fora/UFJF. $18^{\circ}$ Concurso Falcão Bauer

"Beltrame, e. De s. (2013). Meio Ambiente na Construção Civil. Website Eduardo http://www.eduardo.floripa.com.br/download/Artigo_meio_ambiente.pdf“

Bezerra, Francisco Diniz (2020). Análise Setorial Indústria da Construção. Fortaleza: Banco do Nordeste do Brasil, ano 5, n.144, (Caderno Setorial ETENE, n.144)

Empresa Brasil De Comunicação. Expansão do setor pode ser a maior desde 2013. Website da Agencia Brasil EBC. https://agenciabrasil.ebc.com.br/economia/noticia/2020-12/pib-da-construcao-civil-deve-crescer-4-em-2021

FGV/IBRE. Boletim Macro Econômico - Maio 2020 (2020). Website Porta Ibre FGV: https://portalibre.fgv.br/sites/default/files/202005/boletimmacroibre_2005.pdf>

Fonseca, A. L. (2013). Estudo de instalação, organização e manutenção em Canteiro de obras. Trabalho de conclusão de curso. Universidade Federal do Rio de Janeiro, Rio de Janeiro

Gil, A.C. (2008). Métodos e Técnicas de Pesquisa Social. Atlas. São Paulo, SP, Brasil. IBGE. Sistema Nacional de Pesquisa de Custos e Índices da Construção Civil

Marconi, M.A.; Lakatos, E.M. (2006). Fundamentos de metodologia científica. Atlas. São Paulo, SP, Brasil

Mateus, R., Bragança, L. (2006) Tecnologias Construtivas para a Sustentabilidade da Construção. Porto: Edições Ecopy. ISBN 978-989-95194-1-1. 296 p.

Nunes, J. M., Longo, O. C., Alcoforado, L. F., \& Pinto, G. O. (2020). O setor da Construção Civil no Brasil e a atual crise econômica. Research, Society and Development, Article 9. https://doi.org/10.33448/rsd-v9i9.7274

Palacios, V. H. R. Gestão da Qualidade na Construção Civil (1995). Gerenciamento do Setor de Suprimentos em Empresas de Construção de Pequeno Porte, Rio Grande do Sul: Sinduscon - RS

PAIC/IBGE, Pesquisa Anual da Indústria da Construção - PAIC, 2018 (2018) - Website IBEG: https://sidra.ibge.gov.br/pesquisa/paic/quadros/brasil/2018

Rocha Neto, H. S. R. (2010) Avaliação dos índices de desperdícios de materiais: estudo de caso em uma obra de edificação na cidade de Feira de SantanaBa. p. 133. Universidade Estadual de Feira de Santana. Trabalho de conclusão de curso. Feira de Santana/BA

Sacilotti, A. C. (2010) A importância da tecnologia da informação nas micro e pequenas empresas: um estudo exploratório na região de Jundiaí. p. 116. Faculdade Campo Limpo Paulista. Dissertação de mestrado. Campo Limpo Paulista/SP

Schlindwein, N. F. C (2013). Modelo de avaliação da maturidade da gestão de suprimentos em organizações hospitalares. In: simpósio de administração da produção, logística e operações internacionais, São Paulo

Serra, S.M.B. (2001) Canteiro de obras: projeto e suprimentos. São Carlos: UFSCar, 41p. (apostila para o curso de atualização de Racionalização de Processos e Produtos na Construção de Edifícios)

Souza, G. D. (2006). Gestão da cadeia de suprimentos integrada à tecnologia da informação. Rev. Adm. Pública. vol.40 no.4 Rio de Janeiro

Viana, J. C.; Alencar, L. H. (2012). Metodologias para seleção de fornecedores: uma revisão da literatura. Produção, v. 22, n. 4, p. 625-636

IBGE, 2020. Produto Interno Bruto - PIB. Website IBEG: https://www.ibge.gov.br/explica/pib.php

Sidra, Ibge, 2020. Pessoas por Nível de Instrução no Brasil. Website IBEG: https://sidra.ibge.gov.br/tabela/3543\#resultado

Souza, Ubiraci e. L. (2000). Projeto e Implantação do Canteiro. O Nome da Rosa. São Paulo

Pinho, S. A. C. (2013). Desenvolvimento de programa de indicadores de desempenho para tecnologias construtivas à base de cimento: perdas, consumo e produtividade (Dissertação de Mestrado). Escola Politécnica de Pernambuco, Universidade de Pernambuco, Recife

Souza, U. B. L., Paliari, J. C., Andrade, A. C., Agopyan, V. (1998). Perdas de materiais nos canteiros de obras: a quebra do mito. Qualidade na Construção, 2(13), 1-11 
Research, Society and Development, v. 10, n. 9, e55110918407, 2021

(CC BY 4.0) | ISSN 2525-3409 | DOI: http://dx.doi.org/10.33448/rsd-v10i9.18407

Santos, P. R., Santos, D. de G. (2017). Investigação de perdas devido ao trabalho inacabado e o seu impacto no tempo de ciclo dos processos construtivos. Ambiente construído, 17(2), 39-52. doi.org/10.1590/s1678-86212017000200145

Oliveira O. J. (2001). Influências do projeto de produção e do projeto de canteiro no sistema logístico da construção de edifícios, in: Workshop Nacional: Gestão do Processo de Projeto na Construção de Edifícios, São Carlos

Falcão T. F.; Brandstetter M. C. G. O. e Amaral T. G. (2010) Diretrizes estratégicas para melhoria da eficiência logística em canteiros de obra, in: XIII Encontro Nacional de Tecnologia do Ambiente Construído. Rio Grande do Sul

Ferreira E. A. M. (1998). Metodologia para elaboração do projeto do canteiro de obras de edifício, Tese (Doutorado) - Escola Politécnica, Universidade de São Paulo

Silva F. B. e Cardoso F. F. (1998). A importância da logística na organização dos sistemas de produção de edifícios, in: VII Encontro Nacional de Tecnologia do Ambiente Construído, 277-285

Viana, D. D., Formoso, C. F., Kalsaas, B. T. (2012). Waste in construction: a systematic literature review on empirical studies. In Annual Conference of the International group for Lean Construction. San Diego: State University of San Diego

Bohnenberger, J. C., Pimenta, J. F. de P., Abreu, M. V. S., Comini, U. B., Calijuri, M. L.,Moraes, A. P. De, Pereira, I. da S. (2018). Identificação de áreas para implantação de usinade reciclagem de resíduos da construção e demolição com uso de análise multicritério. Ambiente Construído, 18(1), pp. 299-311. doi: 10.1590/s1678-86212018000100222

Li-Yashuai. (2013). Developing a Sustainable Construction Waste Estimation and Management System. (Thesis) Hong Kong University of Science and Technology, HongKong. doi: 10.14711/thesis-b1226942»

Paz, D. H. F., Lafayette, K. P. V. (2016). Forecasting of construction and demolition waste in Brazil. Waste Management \& Research, 34(8), 708-716. //doi.org/10.1177/0734242X16644680»

Pesquisa PMSURVEY.ORG (2014) - The Essential Role of Communications - Problemas mais comuns em projetos. Website Beware: http://beware.com.br/arquivos/Report2014-PMSURVEY.pdf

Vieira, AA, Guimarães, DR \& Soares, WS. (2020). Safety and health in the construction industry: an approach to collective protection measures. Research, Society and Development, 9(7):1-22, e314973768

Lima, Oliveira, \& Martins .(2021). Training as an accident and incident prevention mechanism: case study in a constructor in Belo Horizonte, Minas Gerais. Research, Society and Development, v. 10, n.6, e19610615672

McKinsey Global Institute (MGI). (2016). Which Industries Are the Most Digital (and Why)? by Prashant Gandhi, Somesh Khanna, and Sree Ramaswamy. Website Harvard Business Review: https://hbr.org/2016/04/a-chart-that-shows-which-industries-are-the-most-digital-and-why 